\title{
Study on antimicrobial property of Agaricus bisporus (Button Mushroom)
}

\author{
Sushma Dubey ${ }^{1}$, Jaya Singh², Barkha Nandanwar', Saurabh Gupta ${ }^{2 *}$ and Paras Jain ${ }^{3}$ \\ ${ }^{1}$ Dept of Biotechnology, Kalinga University, Raipur, Chhattisgarh, India \\ ${ }^{2}$ Biodiversity Conservation and Rural Biotechnology Centre (BCRBC), Jabalpur, Madhya Pradesh, India \\ ${ }^{3}$ Department of Botany, Ranchi University, Ranchi, Jharkhand, India \\ *Email: gupta.saurabh89@yahoo.com
}

Received : 17.03.2021; Revised : 07.05.2021 ; Accepted : 08.05.2021

\begin{abstract}
Agaricus bisporus (FCM\#03) sp. provides bioactive compounds that claim to posses antibacterial activity. The aim of this research paper is to know antimicrobial activity of various extract of Agaricus bisporus. Fruiting bodies of Agaricus bisporus (FCM\#03) were extracted by maceration method using acetone, ethanol, methanol and water. The antimicrobial activity of various solvent extracts $(50 \mu \mathrm{g} / \mathrm{ml})$ of Agaricus bisporus were tested against six species of bacteria. The antibacterial activity of methanolic and acetone extract were found to be more Inhibitory effect of these two extract against all bacteria. Fungi toxicity of Agaricus bisporus (FCM\#03) was tested by adopting poisoned food technique. The concentrations of extracts, used in the present study were 100, 250, 500 and 1000 $\mathrm{mg} / \mathrm{ml}$. The acetone extract was the most effective against. F. oxysporum, C. lunata and M. gypsum which were completely inhibited at $500 \mathrm{mg} / \mathrm{ml}$ of concentration.
\end{abstract}

Keywords: Agaricus bisporus (FCM\#03), antimicrobial, bioactive compound.

\section{INTRODUCTION}

A mushroom is defined as "a macro fungus with a distinctive fruiting body which can be either epigeous or hypogenous. The macro fungi have fruiting bodies large enough to be seen with the naked eye and to be picked up by hand" (Chang and Miles, 2004). Edible mushrooms once called the "food of the gods" and still treated as a garnish or delicacy can be taken regularly as part of the human diet or be treated as healthy food or as functional food. The extractable products from medicinal mushrooms, designed to supplement the human diet not as regular food, but as the enhancement of health and fitness, can be classified into the category of dietary supplements/mushroom nutriceuticals (Chang and Buswell, 1996). A nutraceuticals can be defined as a substance that may be considered a food or part of a food that provides medical or health benefits like the prevention and treatment of disease (Cristiane et al., 2016). Mushrooms have become attractive as a functional food and as a source for the development of drugs and nutraceuticals (Lakhanpal and Rana, 2005), responsible with their antioxidant, antitumor (Jones and Janardhanan, 2000) and antimicrobial properties. Besides their pharmacological features, mushrooms are becoming more important in our diet due to their nutritional value, related to high protein and low fat / high energy contents (Agahar-Murugkar and Subbulakshmi, 2005). Agaricus bisporus, known as table mushroom, cultivated mushroom or button mushroom, is an edible basidiomycete fungus which naturally occurs in grasslands, fields and meadows across Europe and North America. It has spread much more widely and is one of the most widely cultivated mushrooms in the world. Oxidation is essential to many living organisms for the production of energy to fuel biological processes. However, the uncontrolled production of oxygen derived free radicals is involved in the onset of many diseases such as cancer, rheumatoid arthritis, and atherosclerosis as well as in degenerative processes associated with aging (Halliwell and Gutteridge, 1984). The aim of present study was to investigate the antimicrobial activity of Agaricus bisporus.

\section{MATERIALS AND METHODS}

\section{Collection of mushroom sample}

Agaricus bisporus (FCM\#03) fruiting bodies were collected from Biodiversity Conservation and Rural Biotechnology Centre, Jabalpur (Madhya Pradesh, India). The fungus sample was maintained in PDA (Potato Dextrose Agar) slant. The strains (FCM\#03) were used in the present study. 


\section{Preparation of the culture media}

Nutrient agar media (NAM) (Agrawal and Hasuja, 1986) and Potato dextrose agar (PDA) media were used in the study for antimicrobial analysis.

\section{Organisms used for evaluation of antimicrobial activity}

In-vitro antimicrobial susceptibility test were performed using a set of microbes such as Gram negative, Gram positive bacteria and fungi. All bacterial and fungal strains were obtained from Collection Center, Biodiversity, Conservation and Rural Biotechnology Centre, (BCRBC), Jabalpur.

The strains used for antibacterial activity were:

- Bacillus subtilis (BCRBC\# 1682)

- Enterococcus faecium*

- Salmonella paratyphi*

- Salamonella typhi (BCRBC\# 250)

- Staphylococcus aureus (BCRBC\#478)

- Klebsiella pneumoniae (BCRBC\# 210)

The strains used for antifungal activity

- $\quad$ Aspergillus niger - FCN\#34

- Aspergillus flavus - FCN \#120 (A-4)

- Fusarium oxysporum - FCN \#80

- Curvularia lunata - FCN \#62

- Alternaria alternata - FCN \#120

- $\quad$ Microsporu M. gypsum - FCN \#I8(MG)

- Sclerotium rolfsii - FCN \#340

Extraction of bioactive compounds from fruiting bodies of Agaricus bisporus (FCM\#03):

In the present study all the parts of fruiting bodies of Agaricus bisporus (FCM\#03) were rinsed separately with distilled water. After that surface sterilized with $70 \%$ ethanol and shade dried in the laboratory. Dry mushroom sample were grinded with the help of grinder machine and were stored in sterile, air tight bottles and were used as extraction. $10 \mathrm{gm}$ of Agaricus bisporus (FCM\#03) powder was subjected to Soxhlet extraction using micro Clevenger type of apparatus for $10 \mathrm{hrs}$ using $100 \mathrm{ml}$ of following solvents viz., ethanol, methanol, acetone and distilled water. Cycles were done 6-10 times and extract was recovered by filtration and extracts were concentrating into 30\% by rotavapour for further analysis (Avnish et al., 2020)

\section{Filter paper disc diffusion method (FDDM)}

Antimicrobial activity of mushroom extract was carried out by following the filter paper disc diffusion technique (Vincent and Vincent, 1944 and Khedoudja et al., 2020 and Paul Njenga et al., 2017). This method is also known as Kirby-Bauer method being recommended by the NCCLS (National Committee for Clinical Laboratory Standards). The antimicrobial properties of different extracts were evaluated in different dilutions and the dilution of mushroom extracts were made by dissolving these extracts into its respective solvents.

A small amount $(1 \mathrm{ml})$ of $18 \mathrm{hrs}$ old suspension of each bacterium was then separately added to Erlenmeyer flasks containing $100 \mathrm{ml}$ sterilized and cooled $\left(40^{\circ} \mathrm{C}\right)$ nutrient agar medium (NAM). Flasks were gently shaken to mix bacterial cells in the medium. Aliquots of $20 \mathrm{ml}$ seeded medium were poured in each sterile petriplates. Sterile filter paper discs (5mm diameter) each impregnated with different dilution of each essentials oil (Methanolic, Ethanolic and Acetone) were placed at equidistance on upper surface of seeded agar medium. The plates were left for $30 \mathrm{~min}$ at room temperature. Antibiotic disc Gentamycin sulfates $(40 \mathrm{mg} / \mathrm{ml})$ were used as a positive control, while discs soaked in respective solvent were used as a blank control. The zone of inhibition formed by each extract in different dilution and controls was recorded after 24 hour of inhibition at $35 \pm 2^{\circ} \mathrm{C}$ for bacteria.

\section{Poisoned food technique (PFD)}

Grover and Moore (1962) adopted to evaluate the effect of herbal extract on the growth of microorganisms. $20 \mathrm{ml}$ of sterilized and cooled $\left(40^{\circ} \mathrm{C}\right)$ growth media (PDA) with desired concentration of antibiotic were poured into presterilized petriplate. Requisite amount of different concentrations of extracts were added into the plates. The assay plates rotated clockwise and anticlockwise to ensure an even distribution of the extract into the medium. In control plates the medium was subjected with respective solvents. After the solidification of agar medium, a disc (5 $\mathrm{mm}$ diameter) of test organism from 7 days old culture was placed aseptically in the centre of each plate. The assay plates were incubated at $28+2^{\circ} \mathrm{C}$ for 7 days. The experiment was run in triplicate. 


\section{RESULTS AND DISCUSSION}

\section{Antimicrobial activity of different extracts of Agaricus bisporus (FCM\#03)}

Results obtained from disc diffusion method revealed that methanolic extracts of Agaricus bisporus (FCM\#03) $(50 \mathrm{mg} / \mathrm{ml})$ showed maximum activity against $B$. subtilis followed by $S$. typhi, $S$. aureus, E. faecium and K. pneumonia, while acetone extracts showed maximum activity against $S$. typhi and minimum against $S$. paratyphi. Water extract showed weak activity against different bacterial strains. Maximum variations were observed in the activity of acetone extract at desire period of temperature and incubation. The results obtained through filter paper disc diffusion method (FDDM) were more or less similar against same set of microbial strains. Determination of antimicrobial activity of Agaricus bisporus (FCM\#03) was performed by adopting disc diffusion, well diffusion and poisoned food plate technique, against set of Gram positive and Gram negative bacterial strains. Similar results have also been obtained by Paul Njenga et al. (2017) and Andrew et al. (2019) regarding antimicrobial activity of mushroom.

\section{Fungi toxic effect by poisoned food technique}

Fungi toxicity of Agaricus bisporus (FCM\#03) was tested by adopting poisoned food technique. The concentrations of extracts, used in the present study were $100,250,500$ and $1000 \mathrm{mg} / \mathrm{ml}$.

The acetone extract was the most effective against. F. oxysporum, C. lunata and M. gypsum which were completely inhibited at $500 \mathrm{mg} / \mathrm{ml}$ of concentration. While growth inhibition of $A$. niger, A. flavus and Sclerotium rolfsii was observed 80.0,
78.5 and $77.7 \%$ respectively at $1000 \mathrm{mg} / \mathrm{ml}$ of concentration.

Ethanolic extract completely inhibited the growth of A. flavus and S. rolfesii at $1000 \mathrm{mg} / \mathrm{ml}$, while at the same concentration $91.1,92.6$ and $82 \%$ inhibition on growth of $A$. niger, F. oxysporum and M. gypsum was inhibited respectively but the same concentration did not sufficiently inhibit the growth of C. lunata and A. alternata.

Activity of methanolic extract was found to be concentration dependents $M$. gypsum was most susceptible to the methonolic extract $50 \%$ reduction in growth was observed at $100 \mathrm{mg} / \mathrm{ml}$ while it was $100 \%$ reduction at $500 \mathrm{mg} / \mathrm{ml} 100 \%$ reduction in C. lunata and S. rolfssi was seen against $1000 \mathrm{mg} /$ $\mathrm{ml}$ of concentration. Rest of the fungal mycelia of A. niger, A. flavus, F. oxysporum and A. alternata were not $100 \%$ inhibited even at $1000 \mathrm{mg} / \mathrm{ml}$ of concentration.

The water extract of the Agaricus bisporus was failed to inhibit the $100 \%$ growth of any of the fungi which has been taken into present study. Maximally $68.8 \%$ of inhibition was observed against $F$. oxysporum at $1000 \mathrm{mg} / \mathrm{ml}$ of concentration. The extract was least effective against $C$. lunata, $A$. alternata, S. rolfsi, A. flavus and A. niger. Mycelial growth of $M$. gypsum was reduced by $60.2 \%$ at 100 $\mathrm{mg} / \mathrm{ml}$. Daniela et al. (2013) reported antifungal peptide designated mushroom which exhibited antifungal activity against pathogenic fungi.

\section{CONCLUSION}

The present study described the status of Agaricus bisporus (FCM\#03) and provided antimicrobial properties and the justification for continuing search for novel drugs. The utilization of Agaricus bisporus compound has excellent

Table 1:Evaluation of antimicrobial activity of different extracts of Agaricus bisporus (FCM\#03).

\begin{tabular}{|c|c|c|c|c|c|c|}
\hline \multirow{2}{*}{$\begin{array}{l}\text { S. } \\
\text { No. }\end{array}$} & \multirow[t]{2}{*}{ Test organisms } & \multicolumn{5}{|c|}{ Zone of inhibition (mm) } \\
\hline & & $\begin{array}{l}\text { Methanol } \\
\left(50 \mu \mathrm{gml}^{-1}\right)\end{array}$ & $\begin{array}{c}\text { Ethanol } \\
\left(50 \mu \mathrm{gml}^{-1}\right)\end{array}$ & $\begin{array}{c}\text { Acetone } \\
\left(50 \mu \mathrm{gml}^{-1}\right)\end{array}$ & $\begin{array}{c}\text { Distilled } \\
\text { water } \\
\left(50 \mu \mathrm{gml}^{-1}\right)\end{array}$ & $\begin{array}{c}\text { Gentamycin } \\
\text { sulphate } \\
\left(40 \mu \mathrm{gml}^{-1}\right)\end{array}$ \\
\hline 1 & Bacillus subtilis & $18.00 \pm 0.21$ & $10.60 \pm 0.37$ & $21.00 \pm 0.00$ & $8.00 \pm 0.33$ & $30.20 \pm 0.04$ \\
\hline 2 & Enterococcus faecium & $21.00 \pm 0.05$ & $15.20 \pm 0.04$ & $20.00 \pm 0.18$ & $10.60 \pm 0.30$ & $34.50 \pm 0.02$ \\
\hline 3 & Salmonella paratyphi & $14.20 \pm 0.08$ & $15.00 \pm 0.01$ & $15.00 \pm 0.33$ & $7.90 \pm 0.08$ & $30.10 \pm 0.02$ \\
\hline 4 & Salamonella typhi & $17.00 \pm 0.12$ & $10.00 \pm 0.01$ & $20.60 \pm 0.19$ & $7.00 \pm 0.06$ & $34.00 \pm 0.01$ \\
\hline 5 & Staphylococcus aureus & $18.30 \pm 0.20$ & $9.00 \pm 0.15$ & $18.00 \pm 0.11$ & $8.00 \pm 0.04$ & $31.00 \pm 0.03$ \\
\hline 6 & Klebsiella pneumoniae & $21.30 \pm 0.08$ & $11.30 \pm 0.10$ & $23.60 \pm 0.12$ & $8.40 \pm 0.02$ & $29.50 \pm 0.07$ \\
\hline
\end{tabular}




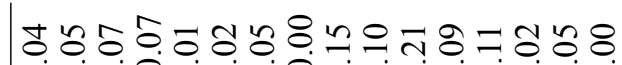
$H+H+H+H+H+H+H+H+H$ 윙ㅇㅇㅇㅇㅇㅇㅇㅇㅇㅇㅇㅇㅇㅇㅇㅇㅇㅇㅇㅇㅇㅇㅇㅇㅇ 他

ミ

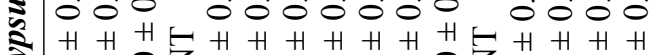

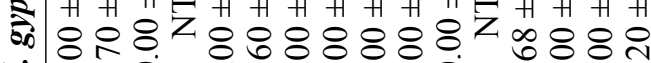
仹

ฐ

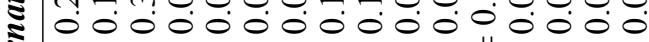
H H H H H H H H H H H H H H H H

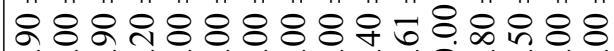

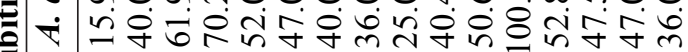

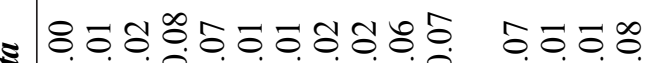

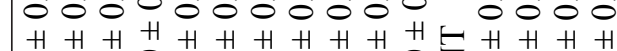

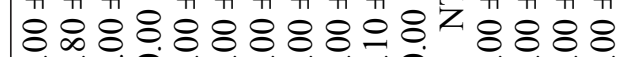

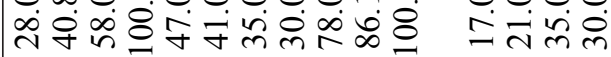

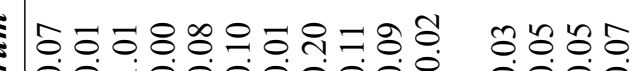

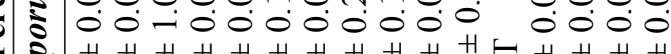
H H H H H H H H H H H

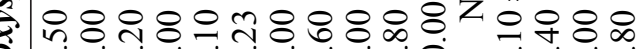
ن i

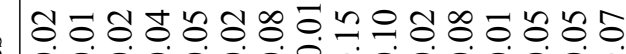

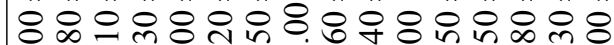
स

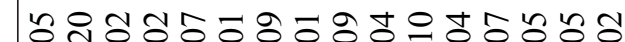

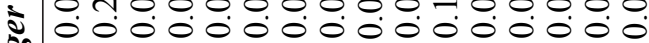
$\stackrel{H}{+}+$ H H H H H H H H H H H H H

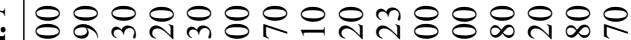

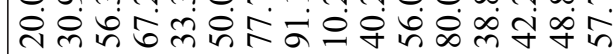

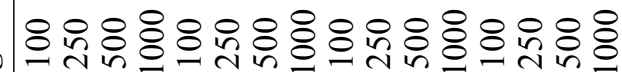
递 potential to discover antimicrobial properties again Bacteria and fungi. The antibacterial activity of methanolic extracts $(50 \mathrm{mg} / \mathrm{ml})$ showed the maximum activity against $B$. subtilis. and the acetone extract was the most effective against. $F$. oxysporum, $C$. lunata and $M$. gypsum which were completely inhibited at $500 \mathrm{mg} / \mathrm{ml}$ of concentration.

\section{ACKNOWLEDGEMENT}

The Authors acknowledge to Research Institute, Biodiversity Conservation and Rural Biotechnology Centre (BCRBC) Jabalpur for Providing Research facilities.

\section{REFERENCES :}

Agahar-Murugkar, D. and Subbulakshmi, G. 2005. Nutritional value of edible wild mushrooms collected from The Khasi Hills of Meghalaya. Food Chem., 89: 599-603.

Agarwal GP and Hasuja SK. 1986. Microorgaisms in the laboratory: A laboratory guide of mycology, Microbiology and plant pathology. Print House, Lucknow, India. 155 pp.

Andrew Nyerere, Christine Bii, and Desta Berhe Sbhatu 2019. Determination of Antimicrobial Activity of Extracts of Indigenous Wild Mushrooms against Pathogenic Organisms. Hindawi- Evidence-Based Complementary and Alternative Medicine. pp.1-7.

Avnish Kumar, Monika Asthana, Preeti Singh, Meenu Katoch, Prabhu Dutt, Sarika Amdekar, Udita Gubrelay, and Rajendra Sharma. 2020. Antioxidant and antibacterial activity of root extracts of Licorice (Glycyrrhiza glabra). International Journal of Minor Fruits, Medicinal and Aromatic Plants, 6 (1): 01- 12.

Benedicts, RG. and Brady, L.R 1972. Antimicrobial activity of Mushroom. J. of Pharma Science, 61: $1820-1822$.

Chang S. T. and Buswell J. A. 1996. Mushroom nutriceuticals. World J. Microb. Biotechnol. 12: 473-476. [A summary of the main features of functional foods/nutraceuticals, nutriceuticals and pharmaceuticals].

Chang ST, Miles, PG. 2004. Mushrooms: Cultivation, nutritional value, medicinal effect, and environmental impact, 2nd ed. CRC Press, Boca Raton, FL. 
Cristiane U.J.O. Limaa ,Eliana F. Grisb and Margô G.O. Karnikowski.2016. Antimicrobial properties of the mushroom Agaricus blazei - integrative review. Revista Brasileira de Farmacognosia, 26: 780-786.

Daniela Nikolovska-Nedelkoska, N. AtanasovaPancevska, H. Amedi and Veleska, D. 2013. Screening of antibacterial and antifungal activities of selected Macedonian wild mushrooms. Journal of Nature and Science, 124: 333-340.

Grover, R.K. and Moore, J.D. 1962. Toximetric Studies of Fungicides against the Brown Rot Organisms, Sclerotinia fructicola and S. laxa. Phytopathology, 52: 876-879.

Halliwell and Gutteridge, 1984 B. Halliwell, J.M.C. Gutteridge Oxygen radicals, transition metals and disease. Biochem. J., 219: 1-14.

Jone,s S. and Janardhanan, KK. 2000. Antioxidant and antitumor activity of Ganoderma lucidum $\begin{array}{llll}\text { (curt ex Fr.). P. Karst-Reshi } & \text { P. }\end{array}$ (Aphyllophoromycetieae) from South India. Int. J. Med. Mushrooms, 2: 195-200.

Khedoudja Kanoun, Chama Zouaouia, Zemri Khalida, Harir Noria, Bousmaha Leila and Abbouni Bouziane. 2020. Demonstration of the antifungal activity of the aqueous macerated extract of pomegranate (Punica granatum Linn.) bark against Rhodotorula sp. International Journal of Minor Fruits, Medicinal and Aromatic Plants, 6 (2): 2835.
Lakhanpal TN, Rana M. 2005. Medicinal and nutraceutical genetic resources of mushrooms. Plant Genetic Resources, 3(2): 288-303.

Paul Njenga Waithaka1, Eliud Mugu Gathuru, Benson Muriuki Githaiga and Keziah Moraa Onkoba. 2017. Antimicrobial Activity of Mushroom (Agaricus Bisporus) and Fungal (Trametes Gibbosa) Extracts from Mushrooms and Fungi of Egerton Main Campus, Njoro Kenya. J Biomedical Sci., 6:3.doi:10.4172/2254-609X.100063.

Smania, A., Dellamonache, F., Smania, E.F.A, Gil, M.L., Benchetrit, L.C. and Cruz, F.S., 1995a. Antibacterial activity of a substance produced by the fungus Pycnoporus sanguineus (Fr.) Murr. J. Etnno Pharma Col., 45: 177-181.

Smania, AJr., , F., Dellmonache Smania, G.F.A. and Cunev, RS. 1997. Antibacterial activity of steroidal compound isolated from Agaricus bisporus applanatum (Res.). Pal. (Aphyllopharmyceti deae) fruit body. Int. J. of Med. Mush., 1: 325-330.

Vincent, J. G. and Vincent, H. W. 1944. Filter paper disc modification of the oxford cup penicillin determination. Proc. Soc. Exp. Biol. Med. 55: 162-164. 